\title{
Posterior Annulus of the Mitral Valve
}

National Cancer Institute

\section{Source}

National Cancer Institute. Posterior Annulus of the Mitral Valve. NCI Thesaurus. Code C127670.

The portion of the mitral valve annulus that attaches to the posterior mitral valve leaflet. 